\title{
Well-Differentiated Adenocarcinoma of the Urinary Bladder with Minimal Deviation Adenocarcinoma-Like Features
}

\section{Kanomata $\mathbf{N}^{1 *}$ and Muramaki $\mathbf{M}^{2}$}

${ }^{1}$ Department of Pathology, Kawasaki Medical School, Kurashiki, Japan

${ }^{2}$ Department of Urology, Kobe University Graduate School of Medicine, Kobe, Japan

\begin{abstract}
Urinary bladder adenocarcinoma is an uncommon disease. The histological diagnosis of bladder adenocarcinoma is usually straightforward. However, bladder carcinoma rarely shows benign-mimicking features. We report on a 64-year-old woman who was diagnosed with urinary bladder adenocarcinoma, which was well differentiated with the features of minimal deviation adenocarcinoma. Most of the tumor cells were slightly atypical, and the tumor was differentiated barely from the benign disease. Careful examination was necessary for a correct diagnosis. The pathology comprised invasive foci with desmoplastic reaction in the extravesicular adipose tissue.
\end{abstract}

Keywords: Minimal deviation adenocarcinoma; Urinary bladder; Adenoma malignum

\section{Introduction}

Urinary bladder adenocarcinoma is a rare tumor, representing between $0.5-2 \%$ of all malignant epithelial tumors of the urinary bladder. It occurs more commonly in males than in females at about 2.6:1. Its diagnosis is often belated and the prognosis is bleak. Urinary bladder adenocarcinoma is classified into subtypes: enteric (colonic), signet ring cell, mucinous (colloid), clear cell, hepatoid, adenocarcinoma not

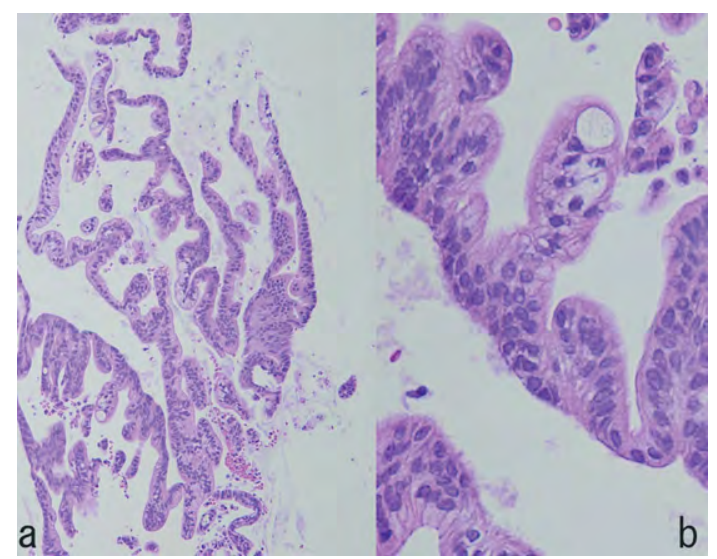

Figure 1: Urinary bladder biopsy specimen showing adenocarcinoma in situ.

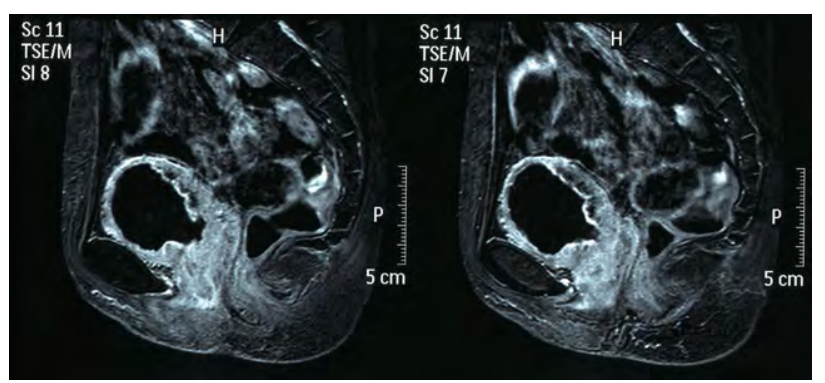

Figure 2: MRI image showing diffuse thickening of the lower to posterior wall of the urinary bladder. Small cysts are present in the bladder wall. otherwise specified, and mixed type [1]. Nephrogenic adenoma, cystitis glandularis and Müllerianosis are important differential diagnoses in bladder adenocarcinoma [2]. Urothelial carcinoma appears rarely as a deceptively benign appearance $[3,4]$. Talbert and Young reported a case of nested variant of urothelial carcinoma with minimal deviation adenocarcinoma-like features [3]. Herein, we report a pure primary adenocarcinoma of the urinary bladder with minimal deviation adenocarcinoma-like features.

\section{Case Report}

A 64-year-old Japanese woman presented complaining of hematuria and lower abdominal pain. A local physician performed a cystoscopy, which revealed an infiltrative lesion with an irregular surface in her urinary bladder. The lesion appeared to invade widely from the urinary bladder neck to the posterior wall. A biopsy showed adenocarcinoma in situ (Figure 1). An MRI scan showed irregular thickening of urinary bladder wall and invasion to the rectum and the vagina was suspected (Figure 2). The patient's serum CA19-9 concentration was high, 3372 $\mathrm{U} / \mathrm{ml}$, and the concentrations of CEA and CA-125 were $1.9 \mathrm{ng} / \mathrm{ml}$ and $18 \mathrm{U} / \mathrm{ml}$, respectively. Pelvic exenteration was performed.

Microscopically, the bladder surface comprised columnar cells with papillary structures. This feature was similar to that observed in the biopsy sample. Tubular and cystic glands were observed throughout the bladder wall (Figure $3 \mathrm{a}$ and $3 \mathrm{~b}$ ). Small, simple tubular glands or cysts measuring up to a few millimeters were present. Papillary structures were seen rarely in these glands. Almost all glands and cysts were present without desmoplastic stromal reactions. The nuclei were minimally atypical and were small and round with a smooth contour

*Corresponding author: Naoki Kanomata, MD, Department of Pathology, Kawasaki Medical School, 577 Matsushima, Kurashiki 701-0192, Japan, Tel: +81-86-462-1111; Fax: +81-86-462-1199; E-mail: kanomata_7@med. kawasaki-m.ac.jp

Received July 26, 2013; Accepted November 04, 2013; Published November 06, 2013

Citation: Kanomata N, Muramaki M (2013) Well-Differentiated Adenocarcinoma of the Urinary Bladder with Minimal Deviation Adenocarcinoma-Like Features. J Cytol Histol 4: 189. doi: 10.4172/2157-7099.1000189

Copyright: (c) 2013 Kanomata N, et al. This is an open-access article distributed under the terms of the Creative Commons Attribution License, which permits unrestricted use, distribution, and reproduction in any medium, provided the original author and source are credited. 


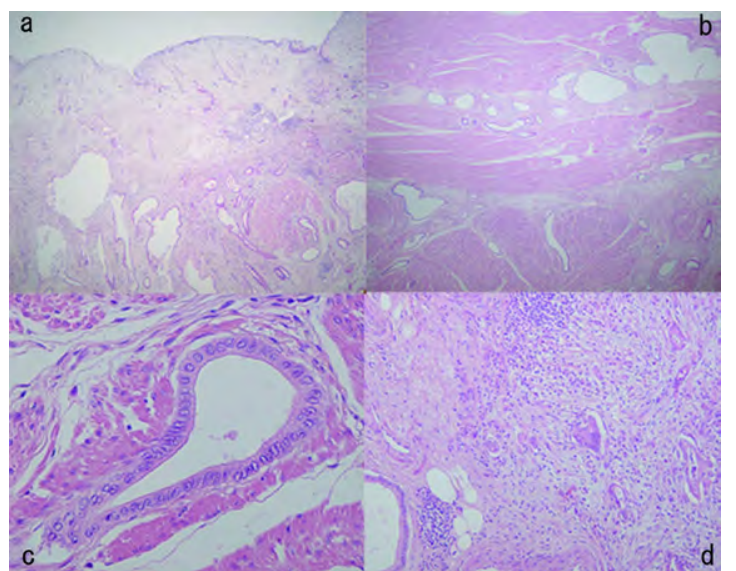

Figure 3: a) Cystectomy specimen b) Tubular glands with minimal stromal reaction c) The nuclei were slightly atypical d) Irregular nests of cells with a desmoplastic reaction were present in the extravesicular adipose tissue.

and without hyperchromasia (Figure 3c). Müllerianosis of the urinary bladder [5] was considered.

Careful examination revealed apparently invasive foci with desmoplastic reactions (Figure 3d), and a diagnosis of adenocarcinoma was made. These clearly malignant features were found mainly in the periphery of the lesion. There was no urothelial carcinoma component. The tumor was staged as pT4aN1. The tumor cells were immunohistochemically CA19-9 +, CK7 +, CK20 +, CA125 -, HIK1083 -, P53 -, and villin -. The Ki-67 labeling index of the benign-appearing glands was $2.5 \%$, while the Ki-67 index of the atypical glands with desmoplastic reaction was up to $30.2 \%$. After the surgery, the serum CA19-9 concentration declined to $94 \mathrm{U} / \mathrm{ml}$, but it increased gradually to $8,014 \mathrm{U} / \mathrm{ml}$ nine months after the surgery. A laparotomy revealed that the tumor was disseminated diffusely along the pelvic bone, and palliative surgery was performed on the recurrent tumor. Although the second surgery failed to remove the tumor completely, the patient remains alive 12 months after the initial surgery.

\section{Discussion}

This was a case of urinary bladder cancer with deceptively benign-appearing features. Given the presence of benign-appearing glands, differentiation from Müllerianosis was challenging, and this case might have been diagnosed as benign Müllerianosis with focal adenocarcinoma. However, the highly elevated CA19-9 concentration before the surgery and the tumor recurrence shortly after surgery did not suggest a focal cancer. Minimal deviation adenocarcinoma of the uterine cervix has benign-appearing glands and only the presence of limited invasive foci suggests the malignant nature of this tumor [6]. The case shares histological features with minimal deviation adenocarcinoma of the uterine cervix, although this was not identical to uterine minimal deviation adenocarcinoma. Talbert and Young reported a case of a nested variant of urothelial carcinoma with minimal deviation adenocarcinoma-like features [3]. To our knowledge, there are no convincing reports of urinary bladder minimal deviation adenocarcinoma without urothelial carcinoma component.
Minimal deviation adenocarcinoma was originally reported in the uterine cervix [7], followed by reports of minimal deviation endometrioid adenocarcinomas [8,9]. One case of gallbladder cancer mimicking minimal deviation adenocarcinoma of the cervix has also been reported [10]. The gallbladder case was positive for HIK1083, which was similar to that of uterine cervical minimal deviation adenocarcinoma.

The histological diagnosis of minimal deviation adenocarcinoma is often challenging because of low stromal reaction, simple tubular structures, and subtle nuclear changes. The diagnosis is especially difficult with limited tumor tissue. Serum CA19-9 and immunohistochemical study are helpful for diagnosis $[11,12]$. A wide excision with or without extensive sampling might be necessary for the correct diagnosis.

\section{References}

1. Ayala AG, Tamboli P, El-Bokainy MN, Schoenberg MP, Oliva E, et al. (2004) Adenocarcinoma. Tumours of the Urinary System and Male Genital Organs. IARC Press, Lyon.

2. Young RH (1997) Pseudoneoplastic lesions of the urinary bladder and urethra: a selective review with emphasis on recent information. Semin Diagn Pathol 14: $133-146$

3. Talbert ML, Young RH (1989) Carcinomas of the urinary bladder with deceptively benign-appearing foci. A report of three cases. Am J Surg Pathol 13: 374-381.

4. Young RH, Oliva E (1996) Transitional cell carcinomas of the urinary bladder that may be underdiagnosed. A report of four invasive cases exemplifying the homology between neoplastic and non-neoplastic transitional cell lesions. Am J Surg Pathol 20: 1448-1454.

5. Young RH, Clement PB (1996) Mullerianosis of the urinary bladder. Mod Pathol 9: 731-737.

6. Tsuda H, Mikami Y, Kaku T, Akiyama F, Hasegawa T, et al. (2003) Interobserver variation in the diagnosis of adenoma malignum (minimal deviation adenocarcinoma) of the uterine cervix. Pathol Int 53: 440-449.

7. Silverberg SG, Hurt WG (1975) Minimal deviation adenocarcinoma ("adenoma malignum") of the cervix: a reappraisal. Am J Obstet Gynecol 121: 971-975.

8. Longacre TA, Hendrickson MR (1999) Diffusely infiltrative endometrial adenocarcinoma: an adenoma malignum pattern of myoinvasion. Am J Surg Pathol 23: 69-78.

9. Mai KT, Yazdi HM, Boone SA (1995) 'Minimal deviation' endometrioid carcinoma with oncocytic change of the endometrium. Arch Pathol Lab Med 119: 751-754.

10. Tashiro T, Hirokawa M, Horiguchi H, Wakatsuki S, Sano T, et al. (2000) Welldifferentiated adenocarcinoma of the gallbladder mimicking minimal deviation adenocarcinoma of the cervix. Apmis 108: 173-177.

11. loffe OB (2005) Recent developments and selected diagnostic problems in carcinomas of the endometrium. Am J Clin Pathol 124: 42-51.

12. MittalK, Soslow R, McCluggage WG (2008)Application of immunohistochemistry to gynecologic pathology. Arch Pathol Lab Med 132: 402-23. 